\title{
Effects of different weed cutting methods on physical and hydromorphological conditions in lowland streams
}

\author{
Jes Jessen Rasmussen ${ }^{\mathrm{a},}$, Helena Kallestrup, Kirstine Thiemer ${ }^{\mathrm{a}}$, Anette Baisner Alnøe, \\ Lisbeth Dalsgaard Henriksen, Søren Erik Larsen and Annette Baattrup-Pedersen
}

Department of Bioscience, Aarhus University, Silkeborg DK-8600, Denmark

Received: 6 October 2020 / Accepted: 10 February 2021

\begin{abstract}
Climate change has increased the frequency and intensity of stream flooding events. In response, managing authorities may increase frequency and intensity of aquatic plant removal (weed cutting) to lower the water level in rivers possibly impairing physical and hydromorphological stream conditions. We studied 32 Danish lowland streams subjected to three different weed cutting practices, representing a gradient in weed cutting intensity, and uncut controls to compare physical and hydromorphological habitat quality parameters among stream groups. Moreover, we measured shortterm changes in dissolved oxygen (DO) concentrations and suspended sediment (SS) transport in two streams before, during, and just after weed cutting for the least and most pervasive weed cutting method, respectively. Our results indicated a lower habitat quality affiliated with increasing intensity of weed cutting practice, notably an association with silt cover at the expense of hard substrate. DO concentrations were relatively unaltered but an abrupt increase in SS transport comparable to storm events was observed during cutting with the most pervasive method. Our results indicate that ecological and hydromorphological effects of high intensity weed cutting should be carefully studied and considered before large scale implementation.
\end{abstract}

Keywords: Stream management / macrophyte removal / physical habitat / sediment transport /

Water Framework Directive

Résumé - Effets des différentes méthodes de faucardage sur les conditions physiques et dromorphologiques des cours d'eau de plaine. Le changement climatique a augmenté la fréquence et l'intensité des inondations des cours d'eau. En réponse, les autorités de gestion sont susceptibles d'augmenter la fréquence et l'intensité de l'enlèvement des plantes aquatiques (faucardage) pour abaisser le niveau de l'eau dans les rivières, ce qui pourrait nuire aux conditions physiques et hydromorphologiques des cours d'eau. Nous avons étudié 32 cours d'eau des basses terres danoises soumis à trois pratiques différentes de faucardage, représentant un gradient d'intensité de faucardage, et des témoins non faucardés afin de comparer les paramètres physiques et hydromorphologiques de la qualité de l'habitat parmi les groupes de cours d'eau. De plus, nous avons mesuré les changements à court terme des concentrations d'oxygène dissous (OD) et du transport des sédiments en suspension (SS) dans deux cours d'eau avant, pendant et juste après la coupe des herbes pour la méthode de coupe la moins et la plus répandue, respectivement. Nos résultats ont indiqué une qualité d'habitat inférieure associée à une intensité croissante de la pratique de faucardage, notamment une association avec une couverture de vase au détriment du substrat dur. Les concentrations d'OD sont restées relativement inchangées, mais une augmentation brutale du transport de MES, comparable à celle des tempêtes, a été observée lors de la coupe avec la méthode la plus répandue. Nos résultats indiquent que les effets écologiques et hydromorphologiques du faucardage à haute intensité devraient être soigneusement étudiés et pris en compte avant une mise en œuvre à grande échelle.

Mots clés : Gestion des cours d'eau / élimination des macrophytes / habitat physique / transport de sédiments / directive-cadre sur l'eau

\footnotetext{
*Corresponding author: ras@niva.no

${ }^{a}$ Present address: Norwegian Institute for Water Research, Section for Freshwater Ecology, Oslo 0349, Norway
} 


\section{Introduction}

The intensive agricultural practice in catchments of European lowland streams entails a need for stream management to reduce the risk of flooding (Eekhout et al., 2015; Baattrup-Pedersen et al., 2018). Consequently, the majority of European lowland streams are channelized, excavated, and dredged (Eekhout et al., 2015). In order to maintain high discharge capacities in excavated and channelized streams macrophyte biomass is often removed (i.e. weed cutting) (Dawson, 1978; Fox and Murphy, 1990; Caffrey, 1993; Old et al., 2014). Weed cutting seeks to optimize drainage of water from agricultural lands by reducing the water retention capacity of the stream (Bal and Meire, 2009).

Weed cutting influences the physical stream environment both directly and indirectly, and at different temporal scales. Besides removal of plant biomass, the main direct short-term effects can be changes in substrate composition, especially in cases of more intensive weed cutting methods (e.g. dredging) (Pedersen et al., 2004; Pedersen and Friberg, 2009; Bal et al., 2017). Indirect short-term effects include decreased water level (Baattrup-Pedersen et al., 2018) and increased current velocity at the reach scale (Curran and Hession, 2013). At the local scale, variability in current velocity (i.e. turbulence) is reduced promoting laminar flow conditions that ultimately may increase sedimentation and dominance of fine particles in the substrate (Pedersen et al., 2011). Increased sedimentation of fine organic sediments may lead to increased microbial biomass and respiration which may ultimately reduce minimum oxygen concentrations towards ecologically critical levels (Pardo and García, 2016). Moreover, increased sedimentation may reduce hyporheic and interstitial flow in gravel beds impeding survival of developing salmonid embryos (e.g. Greig et al., 2007; Wildhaber et al., 2014).

Long-term consequences of repeated weed cutting include modified taxonomic composition of macrophyte communities towards taxonomically homogenous communities dominated by fast-growing species with basal meristem growth points and rhizomes (e.g. Sparganium sp.) (Baattrup-Pedersen et al., 2003). Due to the morphology of Sparganium sp., even dense coverage of this species only creates negligible hydraulic resistance (Bal et al., 2011). Moreover, instead of forming well-defined macrophyte patches, which additionally create a multitude of different physical habitats in terms of substrate and flow conditions (Curran and Hession, 2013; Rovira et al., 2016), Sparganium sp. tends to become uniformly distributed across the stream bed, consequently impeding colonization success of other macrophyte species (Bal et al., 2011). Sparganium monocultures may, therefore, also induce increased homogenization of substrates and flow conditions. Despite the profound effects of weed cutting on the physical instream environment, only a few studies have quantified the physical degradations (Baattrup-Pedersen and Riis, 1999, 2004; Old et al., 2014), whereas most studies focus on hydrological effects such as current velocity, discharge capacity, hydrological resistance, and water level in relation to flooding risk (e.g. Bal and Meire, 2009; Bal et al., 2011; Curran and Hession, 2013) and on nutrient transport (e.g. Verschoren et al., 2017). Although the implications of weed cutting for physical and hydromorphological quality elements can be severe, it may also depend on weed cutting method used and on pattern of weed cutting (e.g. mosaic pattern vs clear-cut stream channel) (Bal et al., 2011; Bal et al., 2017).

Multiple types of weed cutting equipment exist including excavators, boats mounted with automatic knives, and scythes (Baattrup-Pedersen et al., 2002). Excavators are used for dredging and total removal of macrophytes in small channels and streams primarily in agricultural catchments. Weed cutting by boat is performed in deep, non-wadable streams while scythes can be used in small streams with low water levels. Weed cutting using boat or scythe typically aims to remove macrophyte biomass above the substrate in the main flow channel, whereas submergent vegetation can remain along the stream banks (Baattrup-Pedersen and Riis, 2004).

Recently, an alternative weed cutting method was introduced in the Northern part of Denmark aiming to reduce dominance of especially Sparganium sp. in streams with historically frequent and intense cutting practice. A boat mounted with knives is the basic prerequisite for the method, but the cutting strategy is different from the traditional methods. Heavy equipment is used to ensure that the mounted knives are forced into the stream bed aiming to remove rhizomes from disturbance tolerant macrophyte species such as Sparganium sp. While it is questionable to embark upon an alternative weed cutting process that further dissects and mobilizes rhizomes and other vegetative fragments in stream systems dominated by plant species specialized in vegetative dispersal, further negative consequences may include massive mobilization of fine sediments and boosted microbial respiration as the mobilized fine sediment enters the oxygenated water column. These potential negative aspects have not been considered before implementing this alternative weed cutting method but should receive attention before propagating the method to new stream systems.

In the present study, we aimed to quantify the effects of different weed cutting methods on the physical quality and complexity of in-stream habitats. We used 32 small to mediumsized Danish lowland streams subject to three different weed cutting methods: (i) boat (deep, in the river bed), (ii) boat (shallow, above the river bed), and (iii) scythe, and streams without weed cutting as control. Additionally, we performed short-term experiments on sediment transport, oxygen concentrations, and biological oxygen demand (BOD) before, during, and after weed cutting in two streams subjected to weed cutting with scythe and boat (deep), respectively. We hypothesized that (i) weed cutting generally increases substrate homogeneity (increased coverage of sand and silt) compared to streams without weed cutting, (ii) increasing intensity of weed cutting increases substrate homogeneity and decreases the overall physical habitat quality, (iii) short-term sediment mobilization and microbial oxygen consumption will substantially increase, potentially exceeding thresholds for ecological effects, in streams subjected to weed cutting with boat (deep) but not to weed cutting using scythe.

\section{Material \& methods}

\subsection{Study site description}

The study was conducted in 32 lowland streams situated in Eastern Jutland, Denmark (Fig. 1). All streams had comparable 

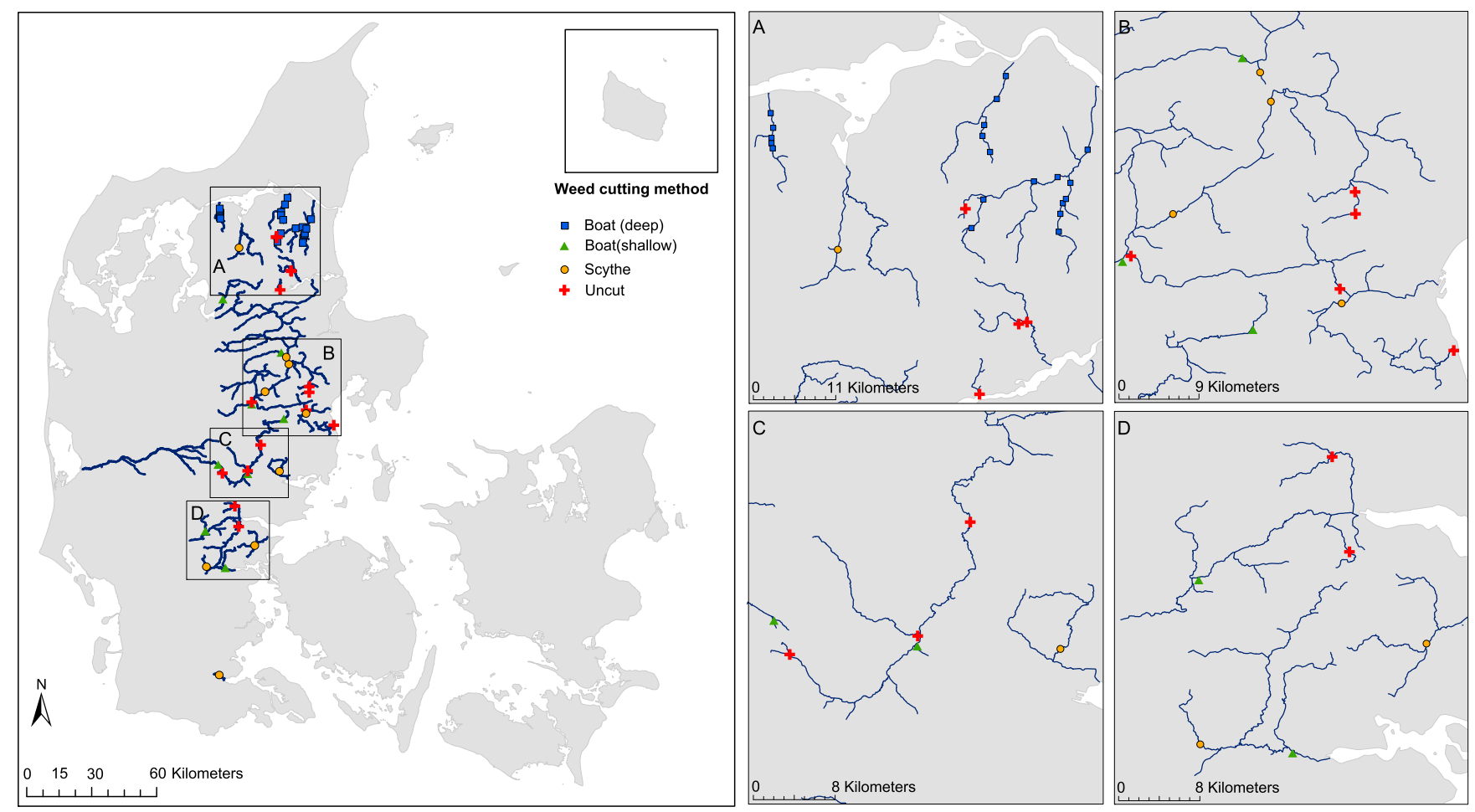

Fig. 1. Geographic locations of study stream reaches.

Table 1. Information on weed cutting practice in studied stream reaches, obtained from questionnaire answers from the municipalities.

\begin{tabular}{lllll}
\hline$n_{\text {streams }}$ & $n_{\text {reaches }}$ & $n_{\text {annual weed cuttings }}$ & Weed cutting method & Weed cutting equipment \\
\hline 12 & 43 & 0 & Uncut & Uncut \\
10 & 27 & $1-3$ & Central (shallow) + selective cutting & Scythe \\
6 & 24 & $1-3$ & Central (shallow) + selective cutting & Boat \\
4 & 20 & $2-5$ & Central (deep) & Boat \\
\hline
\end{tabular}

${ }^{1}$ Selective cutting targeting primarily Sparganium sp. and Elodea sp.

geomorphological conditions consisting partly of former marine sand and partly of glacial meltwater sand and gravel. In order to ensure comparability of stream size and flow inertia among selected streams, the following selective criteria were applied: (1) stream width $>3$ meters and (2) slope between 0.1 and $1 \%$. Stream reaches $(100 \mathrm{~m})$ were selected in each stream, most streams were represented with more than one reach (total $n=114$, Tab. 1, Fig. 1). Note that on multiple occasions, stream reaches subjected to different weed cutting methods were located within the same stream system (Fig. 1). Uncut stream reaches were more abundant compared to stream reaches subjected to different weed cutting methods (Tab. 1). Total catchment area and the relative proportion of agriculture was assessed for each stream catchment $(n=32)$ using ESRI ArcGIS 9.2. Catchment area was quantified according to topography using a $0.5 \mathrm{~m}$ Digital Elevation Map $(50 \times 50 \mathrm{~m})$. Proportional coverage of intensive agriculture was included as supporting parameter as it influences general needs for high stream discharge capacities in order to protect crops from flooding.
The stream reaches were categorized based on weed cutting method: (1) scythe: weed cutting approximately $10 \mathrm{~cm}$ above the stream bed using a scythe specifically targeting disturbance tolerant species, (2) boat (shallow): weed cutting approximately $10 \mathrm{~cm}$ above the stream bed using a boat mounted with automatic knives, (3) boat (deep): weed cutting using a boat with automatic knives forced into the streambed, and (4) uncut: without weed cutting since 2004 (Fig. 1, Tab. 1). The intensity, in terms of the potential for causing ecological impairment, of the weed cutting practices were ranked in degressive order as boat (deep), boat (shallow), scythe, and uncut. Information on weed cutting methods were assembled from questionnaires sent to the municipalities with management obligations in the studied streams (Tab. 1). The reported weed cutting frequency for each stream reach was based on the existing River Basin Management Plans (RBMP). Hence, the reported weed cutting frequency should generally be applicable for all years (2010-2015), although deviations may have occurred due to extremely dry or wet years, consequently requiring less or more intense cutting practice. In general, 
weed cutting was performed from June to October. Lastly, stream reaches with the weed cutting practice boat (deep) were clustered in north-east Denmark where this new alternative weed cutting method has been used.

\subsection{Physical habitat quality}

We characterised the physical habitat quality in 20 reaches subjected to cutting with boat (deep) in 2016, while data for all other stream reaches were surveyed as part of the Danish monitoring program (NOVANA) during the latest complete water plan cycle (2010-2015). In both cases, data were collected according to the national technical guidance document for the Danish Habitat Index (DHI) (Technical Guidance Document V05) (described below) in spring (March-May). For the habitat surveys conducted as part of the Danish monitoring program, each stream reach was surveyed once per water plan cycle (6 years). Hence, survey years differ among the selected stream reaches and were consistently conducted prior to the first weed cutting in the respective survey year.

The DHI is based on 17 physical and hydromorphological parameters. The parameters represent three spatial scales; reach scale, local scale, and habitat scale and is partly based on assessments performed along 10 equidistant transects positioned within the $100 \mathrm{~m}$ reach (Supplementary material, Tab. S1). Number of pool-riffle sequences, sinuosity, crosssectional profile, width of undisturbed area in the riparian zone, and intensity of ochre pollution were assessed visually for the entire reach. The remaining 12 parameters were assessed in each transect, and the mean value of each parameter was calculated. Each parameter was scaled to a value between 0 and 3 . The scale value corresponds to a percentage interval or in some cases a range from modified to natural (Tab. S1). Each scale value was weighted either positive or negative with a factor based on the estimated significance for ecological quality elements (Tab. S1). Summing the weighted scale values for all parameters gives the DHI index value. The DHI index score ranges from -12 to 63 , where increasing index scores reflects increasing habitat quality.

\subsection{Sediment transport in dybvad (boat deep) and sonderup (scythe) streams}

Automatic ISCO samplers were deployed immediately upand downstream of the reaches subjected to weed cutting for the quantification of short-term changes in suspended sediment concentrations $\left(\mathrm{mg} \mathrm{L}^{-1}\right)$. Weed cutting was conducted on 3.6 and $2.1 \mathrm{~km}$ of the Dybvad and Sonderup streams, respectively. The ISCO samplers were deployed approximately $3 \mathrm{~h}$ before weed cutting and removed approximately $24 \mathrm{~h}$ after weed cutting. Water was pumped into $1 \mathrm{~L}$ glass bottles with $20 \mathrm{~min}$ intervals from a well-mixed area of the stream. Weed cutting with scythe in Sonderup stream was conducted on June 29th, 2016 and executed in the upstream direction by two people in waders. Cutting targeted only Sparganium sp. and Elodea sp. leaving some plant patches untouched and others cut. Weed cutting with boat (deep) in Dybvad stream was conducted on June 4th, 2016 and executed in the downstream direction by
3 boats (lined behind each other) with similar weed cutting equipment.

Water samples were stored in cooling boxes, transported to the laboratory and kept frozen $\left(-20^{\circ} \mathrm{C}\right)$ until analysis. Suspended sediment concentrations were quantified for all samples by filtering $100-500 \mathrm{ml}$ of water through a precombusted and pre-weighed $1.2 \mu \mathrm{M}$ Whatman glass microfibre filter. The filters were dried at $60^{\circ} \mathrm{C}$ for $24 \mathrm{~h}$ and re-weighed on Mettler Toledo scale (accuracy $0.001 \mathrm{~g}$ ).

Deposited sediment $\left(\mathrm{g} \mathrm{DW} \mathrm{m}^{-2}\right.$ ) during weed cutting was also quantified in Dybvad stream using six sediment traps. The sediment traps were deployed immediately downstream of the stream reach subjected to weed cutting at the time of initiated weed cutting and were removed at the end of the weed cutting. The sediment traps were modified versions of Rubin boxes previously applied to evaluate effects of fine sedimentation rates on trout egg hatching success (Rubin, 1995; Österling, 2018). The trap (height $25 \mathrm{~cm}$, diameter $10 \mathrm{~cm}$ ) walls and bottom consisted of polypropylene, and each trap was filled with round and washed gravel and stones to maintain the trap in position. Each trap was carefully forced into the bed sediment until the trap edges were located approximately $1-2 \mathrm{~cm}$ above the sediment surface. A plastic bag was used to seal the trap opening while deploying it in the stream bed to ensure that sediment did not enter the traps during deployment. Similarly, plastic bags were used to seal trap openings while removing the traps from the stream bed. After removal, the sediment traps were transported to the laboratory, the boulders were rinsed in tap water and removed, and the remaining sediment material was placed at $60^{\circ} \mathrm{C}$ and dried until constant mass. The dry weight (DW) of the deposited sediment was weighed on a Mettler Toledo (accuracy $0.001 \mathrm{~g}$ ) scale.

\subsection{Dissolved oxygen and BOD in dybvad (boat deep) and sonderup (scythe) streams}

Dissolved oxygen (DO) $\left(\mathrm{mg} \mathrm{L}^{-1}\right)$ was measured before, during, and after weed cutting in Dybvad (boat deep) and Sonderup (scythe) streams using miniDOT (Precision Measurement Engineering, California, USA) deployed up- and downstream of the reaches subjected to weed cutting (similar to the ISCO samplers mentioned above). Logging interval was set to $10 \mathrm{~min}$, and the miniDOT loggers measured DO from at least $3 \mathrm{~h}$ before to at least $24 \mathrm{~h}$ after weed cutting.

Water samples for BOD measurements were collected upand downstream of the reach subjected to weed cutting in Dybvad and Sonderup streams. The water samples were collected in $1 \mathrm{~L}$ glass bottles with $1 \mathrm{~h}$ intervals from $1 \mathrm{~h}$ before weed cutting to approximately $24 \mathrm{~h}$ after weed cutting. The water samples were stored in ice-boxes and transported to the laboratory for analysis. BOD was measured immediately after receiving the water samples using the dilution method (i.e. incubation in darkness at $20^{\circ} \mathrm{C}$ for 5 days) according to European standards (DS/EN 1899 1999).

\subsection{Data treatment}

Comparability of hydromorphological variables among the four treatment groups was tested using linear mixed effects models with a spatial correlation structure fit by maximum 
Table 2. Key physical properties shown as mean, maximum, and minimum values for stream sites subjected to weed cutting by boat (deep), boat (shallow), scythe, and uncut.

\begin{tabular}{|c|c|c|c|c|c|c|c|c|c|c|}
\hline \multirow{2}{*}{$\begin{array}{l}\text { Treatment } \\
\text { group }\end{array}$} & \multicolumn{2}{|c|}{ Slope (\%o) } & \multicolumn{2}{|c|}{ Width (m) } & \multicolumn{2}{|c|}{ Depth (m) } & \multicolumn{2}{|c|}{ Catchment area $\left(\mathrm{km}^{2}\right)$} & \multicolumn{2}{|c|}{$\%$ Agriculture in catchment } \\
\hline & Average & Range & Average & Range & Average & Range & Average & Range & Average & Range \\
\hline Boat (deep) & 0.27 & $0.01-0.66$ & 6.7 & $2.6-12.1$ & $0.74^{\mathrm{A}}$ & $0.38-1.04$ & $78.6^{\mathrm{AB}}$ & $11.1-31.3$ & 58 & $35-74$ \\
\hline Boat (shallow) & 0.21 & $0.16-0.44$ & 6.1 & $3.1-10.8$ & $0.76^{\mathrm{A}}$ & $0.33-1.48$ & $533.8^{\mathrm{A}}$ & $5.7-1818.3$ & 62 & $22-80$ \\
\hline Scythe & 0.35 & $0.19-0.77$ & 4.4 & $3.2-5.4$ & $0.48^{\mathrm{B}}$ & $0.13-0.96$ & $104.4^{\mathrm{B}}$ & $5.8-306.1$ & 68 & $33-80$ \\
\hline Uncut & 0.41 & $0.20-0.75$ & 4.9 & $3.1-15.4$ & $0.34^{\mathrm{B}}$ & $0.12-0.96$ & $44.0^{\mathrm{B}}$ & $2.3-377.4$ & 68 & $43-84$ \\
\hline
\end{tabular}

Values on slope, width, and depth are based on measurements in August-September. Catchment area and \% agriculture in catchment were quantified using GIS. Capital letters indicate significant differences (Bonferroni post hoc test, $\mathrm{p}<0.05$ ).

likelihood. Treatment group was set as a fixed effect and stream site, reflecting interdependence between stream reaches, was included as a random effect. A spatial correlation structure was added to the model to correct for geographical dependencies between stream reaches with different weed cutting practices. Accounting for stream variance and spatial dependencies were expected to reduce error in the models and increase the ability to detect any effect of the weed cutting treatments. Similarly, potential differences in DHI among treatment groups were analysed using a linear mixed effects model with spatial correlation structure fit by maximum likelihood. Treatment group, slope, depth, and catchment area were set as fixed effects and stream was included as a random effect. For significant effects, pairwise tests were performed using Bonferroni post hoc procedure due to unequal sampling size among the four treatment groups. All data were tested for normality (Shapiro-Wilk test, $p>0.05$ ) and homogeneity of variance (Bartlett's test, $p<0.05$ ) before parametric tests were performed. We used a Principal Components Analysis (PCA) to visualize potential generic differences in hydromorphological conditions among the treatment groups. Furthermore, statistically significant grouping of treatment groups in the first two dimensions of the PCA was tested using one-way ANOVA on the PCA coordinates followed by a Student's t-test in case of significant ANOVA. All statistical tests were performed in R ( $\mathrm{R}$ Core Team, 2020) using the following packages: nlme (Pinheiro et al., 2020), multicomp (Hothorn et al., 2008), and vegan (Oksanen et al., 2018).

\section{Results}

\subsection{General hydromorphological conditions}

Mean width (m) and slope (\%o) were not significantly different among the treatment groups (Linear mixed models, $p=0.222$ and $p=0.092$ respectively). Mean width ranged between 4.47 and $6.72 \mathrm{~m}$, and mean slope ranged between 0.20 and $0.41 \%$ (Tab. 2). Mean depth (m) was significantly different among treatment groups (Linear mixed model, $p<0.0001$ ), where stream reaches cut with boat (deep) and boat (shallow) were deeper compared to reaches cut with scythe and uncut reaches (Bonferroni post hoc test; Tab. 2). The proportion of agriculture in the stream catchments was not significantly different among treatment groups (Linear mixed model; $p>0.05$ ) and ranged between 58 and $68 \%$. Catchment area ranged between 44 and $533.8 \mathrm{~km}^{2}$ and was significantly different among the treatment groups (Linear mixed model; $p=0.0044$ ) with stream reaches cut with boat (shallow) having a significantly larger catchment area compared to stream reaches cut with scythe and uncut reaches (Bonferroni post hoc test, $p=0.0123$ and $p=0.0023$ respectively; Tab. 2).

\subsection{Substrate composition}

The coverage of boulders, silt, and gravel were significantly different among the treatment groups (Linear mixed models, $p<0.05)$. The mean coverage of gravel was significantly higher in stream reaches cut with boat (shallow), scythe, and uncut stream reaches compared to stream reaches cut with boat (deep) (Linear mixed model, $p=0.005$, Bonferroni post hoc test; $p<0.05$; Fig. 2). Coverage of boulders and silt were not significantly different among the treatment groups boat (shallow), scythe, and uncut but all three treatment groups were significantly different from boat (deep) (Bonferroni post hoc test, $p<0.0001$; Fig. 2). Stream reaches cut with boat (deep) showed the highest coverage of silt and the lowest coverage of boulders and gravel (Fig. 2). The mean proportional coverage of sand was not significantly different among the treatment groups (Linear mixed model, $p=0.44$; Fig. 2).

\subsection{DHI index scores}

The DHI index score was significantly different among treatment groups (Linear mixed model; $p<0.0001$; Fig. 3). The DHI index score in stream reaches cut with boat (deep) was significantly lower compared to all other treatment groups (Bonferroni post hoc test; $p<0.0001$; Fig. 3). No further significant differences in DHI index scores were found among treatment groups (Bonferroni post hoc test; $p>0.05$ ). Moreover, slope and depth were both significant predictors for DHI index values (Linear mixed model, $p=0.0457$ and $p=0.0334$ respectively). Catchment area did not have any significant effect on the DHI index values (Linear mixed model, $p=0.4999$ ).

The first and second axes of the PCA biplot based on data for all physical and morphological parameters in the DHI index explained $31.8 \%$ and $10.4 \%$ of the data variation, respectively (Fig. 4). The PC1 and PC2 coordinates were significantly different among the treatment groups (one-way ANOVA; $p<0.0001)$. PC1 coordinates for boat (deep) were significantly 

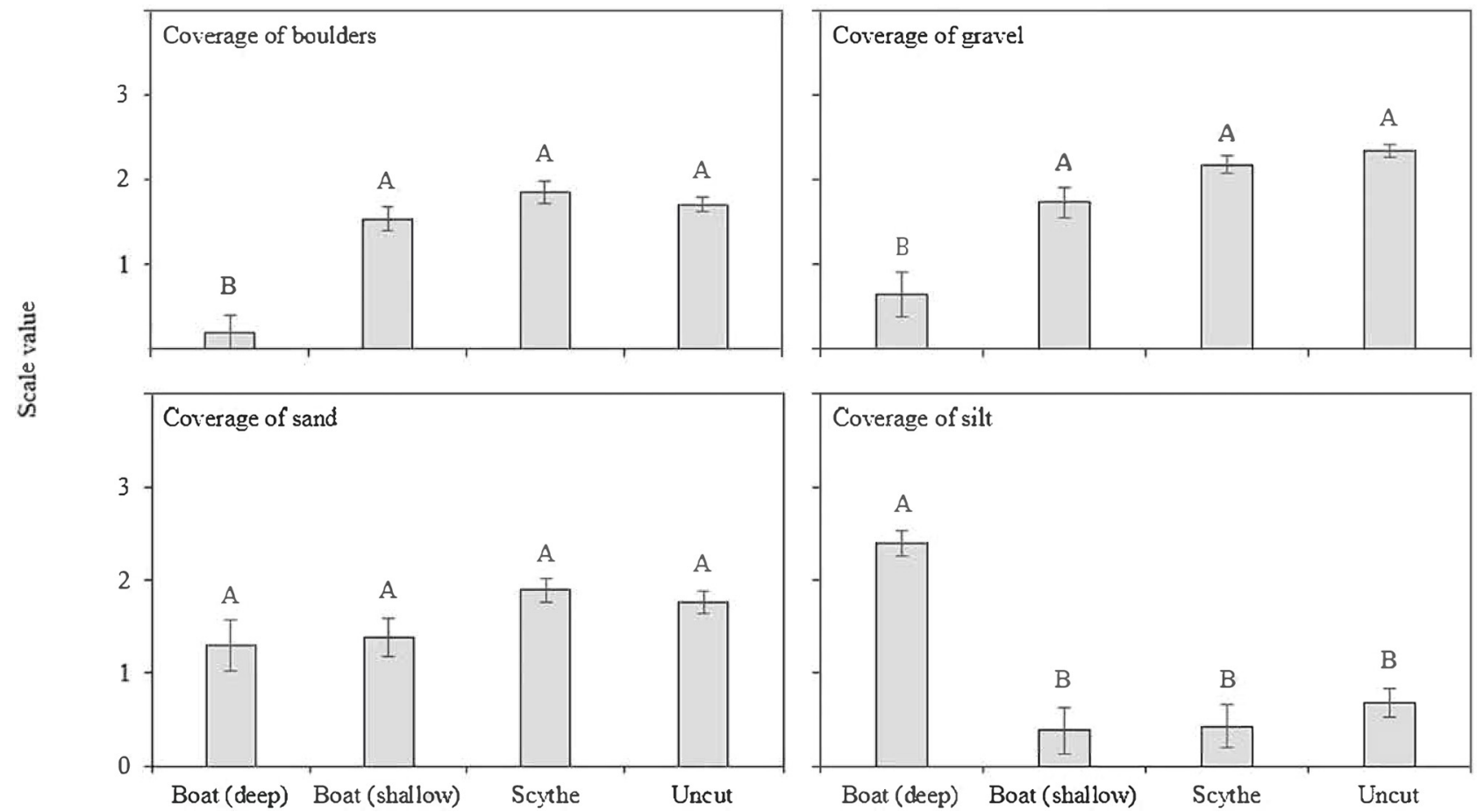

Fig. 2. Mean coverage of boulders, gravel, sand, and silt for the treatment groups boat (deep), boat (shallow), scythe, and uncut. For intervals corresponding to scale values see Supplementary material Table S1. Capital letters indicate significant differences between groups (Bonferroni post hoc test; $<0.05$ ) where treatment groups with different capital letters are significantly different. Error bars indicate standard error.

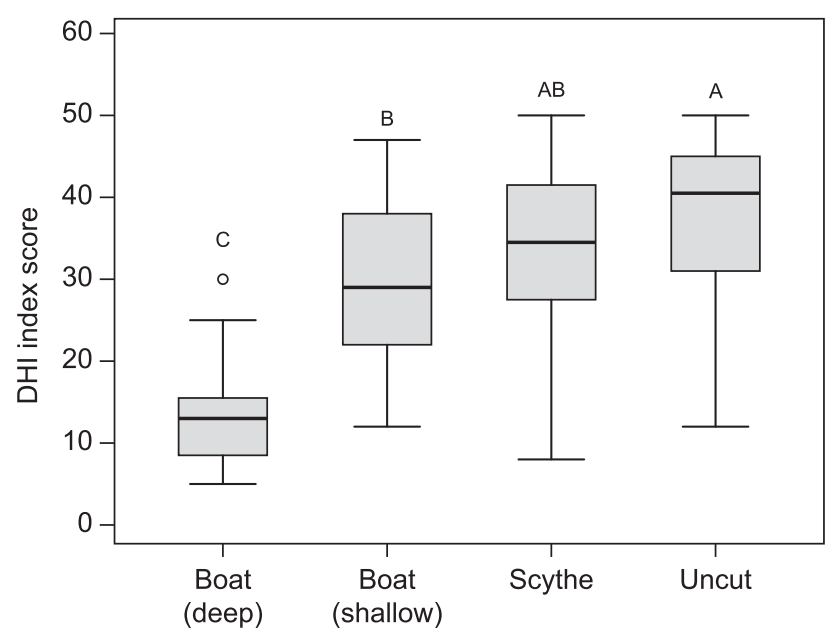

Fig. 3. Total DHI index score for the treatment groups boat (deep), boat (shallow), scythe, and uncut. Letters indicate significant differences between groups (Bonferroni post hoc test; <0.05) where treatment groups with different capital letters are significantly different. Whiskers indicate $95 \%$ confidence interval. The bottom of the box indicates $\mathrm{Q}_{1}$, the middle line indicates the median, and the top of the box indicates $\mathrm{Q}_{3}$.

different from the $\mathrm{PC} 1$ coordinates of all other treatment groups (Student's $t$-test; $p<0.001)$. In general, data points representing boat (deep) cutting were positioned to the lower left of the

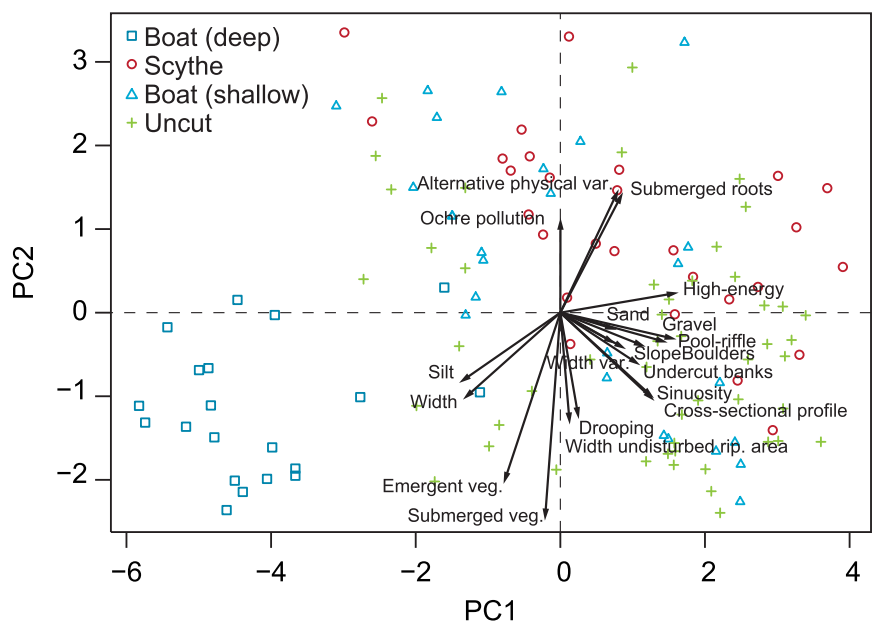

Fig. 4. PCA showing the location pattern of the treatment groups boat (deep), boat (shallow), scythe, and uncut in correlation to each other and to the DHI parameters.

ordination space positively correlating with proportional coverage of silt and average stream width and negatively correlating with submerged roots, alternative physical variation, and high energy flow types (Fig. 4). Data points representing uncut stream reaches were generally positioned to the lower right of the ordination space most strongly correlating with sinuosity and unaltered cross-sectional profiles (positive correlations) (Fig. 4). Based on PC2 coordinates, uncut stream 
reaches were significantly different from reaches cut with boat (shallow) and scythe (Student's $t$-test; $p<0.05$ ) but not significantly different from the boat (deep) treatment group (Student's $t$-test; $p>0.05$ ). Data points positioned in the lower part of the ordination space were positively correlated with proportional coverage of both submerged and emergent vegetation (Fig. 4). No further significant differences were found among treatment groups based on $\mathrm{PC} 1$ or PC2 axis scores (Student's $t$-test; $p>0.05$ ).

\subsection{Sediment transport, oxygen, and BOD}

Suspended sediment transport, DO, and BOD responded with different patterns to weed cutting with boat (deep) (Dybvad stream) and scythe (Sonderup stream) (Fig. 5). In Dybvad stream, suspended sediment transport increased up to a factor of 30 to $150-300 \mathrm{mg} \mathrm{L}^{-1}$ during weed cutting with boat (deep) with elevated suspended sediment concentrations extending approximately 90 minutes post cutting (Fig. 5A). BOD followed a similar pattern increasing from 2 to $4 \mathrm{mg} \mathrm{L}^{-1}$ during cutting with the elevated BOD levels extending approximately $90 \mathrm{~min}$ post cutting (Fig. 5B). The DO concentrations abruptly decreased from 6.0 to $5.3 \mathrm{mg} \mathrm{L}^{-1}$ with the reduced level in DO extending approximately $60 \mathrm{~min}$ post cutting (Fig. 5C). Responses to the cutting method using scythes in Sonderup stream was less pronounced with a slight increase in suspended sediment transport from 10 to $20 \mathrm{mg} \mathrm{L}^{-1}$ and in BOD from 1.7 to $2.2 \mathrm{mg} \mathrm{L}^{-1}$ during cutting (Fig. 5D and $5 \mathrm{E}$, respectively). Concentrations of DO were not visibly influenced by cutting with scythe (Fig. 5F).

Sediment deposition during boat (deep) weed cutting in Dybvad stream varied by a factor of approximately 5 among sediment traps and averaged $>1 \mathrm{~kg} \mathrm{DW} \mathrm{m}^{-2}$ of deposited sediment (Tab. S2).

\section{Discussion}

\subsection{General hydromorphological conditions}

Mean water depth was significantly higher for stream reaches subjected to weed cutting with boat (deep) and boat (shallow) compared to uncut reaches and reaches cut with scythe. Moreover, total catchment area of stream reaches subjected to cutting with boat (shallow) was a factor of 5-12 higher compared to all other treatment groups. Firstly, these results indicate that treatment type was not truly independent of environmental factors as boat-based methods were only used in streams with sufficient depth and wading-based methods were not performed in streams with significant parts of the reaches exceeding $90-100 \mathrm{~cm}$ due to safety issues. Secondly, as average stream width and depth in theory should be linearly correlated with catchment size (Frasson et al., 2019), stream reaches subjected to boat (deep) cutting appeared overly deep and wide relative to their catchment sizes compared to all other treatment groups suggesting a historic more intense management to ensure high discharge capacity. These results further indicate that potential significant differences in hydromorphological conditions among treatment groups should not be interpreted as unbiased cause-effect relationships as management options were partly selected based on prevailing hydromorphological conditions. Conversely, our results also suggest that any comparison of effects of different weed cutting methods inevitably will be confounded by non-overlapping hydromorphological properties (especially stream depth) among treatment groups due in part to safety issues with wading in deeper streams and the logic restrictions of boat-based methods in shallower streams.

\subsection{Effects of weed cutting methods on substrate composition}

We found that the most intensive weed cutting method, boat (deep), was associated with the strongest deviation in substrate composition compared to uncut streams and streams subjected to other weed cutting methods. As such, the proportional coverage of boulders and gravel was significantly lower and the proportional coverage of silt significantly higher in streams subjected to weed cutting with boat (deep) compared to all other treatment groups. In addition, the proportional coverage of gravel was significantly lower in streams subjected to weed cutting with boat (shallow) compared to uncut controls. However, we found no consistent support of our second hypothesis that substrate composition increasingly changes from hard substrates (boulder and gravel) to more soft types (sand and silt) with increasing intensity of weed cutting. This could be due to sand often being the dominant substrate type in lowland streams as the catchment often consists of moorland plains (e.g. Verdonschot and Nijboer, 2002; Leggieri et al., 2013). Secondly, a considerable amount of the streams subjected to weed cutting with boat (shallow), scythe, and uncut controls were characterized by pronounced agricultural activity in the catchments (Tab. 2). This implies a potential historic impact (previous dredging and channelization) as well as erosion processes transporting significant amounts of fine particles from agricultural fields to the streams (Kronvang et al., 1997; Lamba et al., 2015). Finally, the high similarity in substrate composition among streams subjected to weed cutting with boat (shallow), scythe, and uncut controls could indicate that boat (shallow) and scythe only marginally impairs physical habitat conditions in streams. However, this is contrasted in the existing literature showing that $e . g$. weed cutting increased current velocity at the reach scale which increased sediment erosion ultimately governing a more homogenous substrate composition (Old et al., 2014). Alternatively, the observed differences in substrate composition may have existed before the introduction of present weed cutting methods and partly been a premise for the methodological choices of weed cutting. For example, the boat (deep) method appear as a better fit for deep streams with predominantly soft substrate types whereas presence of significant proportions of cobble and boulders may have favoured other types of weed cutting. Nevertheless, the boat (deep) method was recently introduced in River Guden in a Natura 2000 area where the stream is characterised by natural meandering and substantial fractions of hard substrate types (although no large boulders) (own observations). This shows that the boat (deep) method can be conducted in other types of streams than those dominated by soft substrates. 


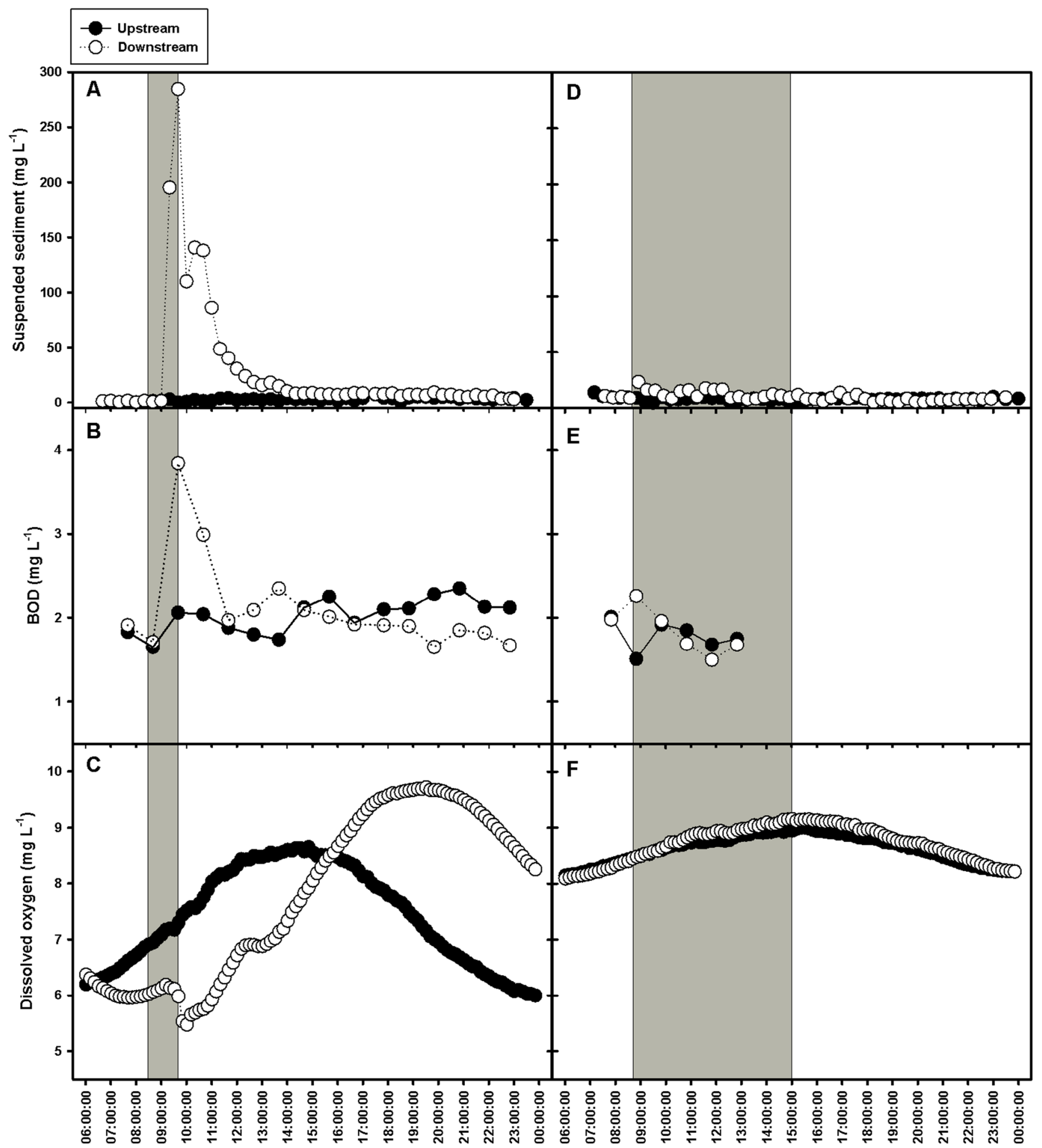

Fig. 5. Suspended sediment concentrations (A, D), BOD (B, E), and dissolved oxygen concentrations (C, F) as a function of time before, during, and after weed cutting with the boat (deep) method (A, B, C) and scythe (D, E, F) in Dybvad and Sonderup stream, respectively. The grey area signifies the time for active weed cutting. Open and closed symbols represent measurements conducted up- and downstream of the stream reach subjected to weed cutting, respectively.

\subsection{Effects of weed cutting practice on general stream habitat quality}

The habitat quality (DHI scores) was not consistently lower in streams subjected to weed cutting compared to uncut controls. However, DHI scores generally decreased with increased intensity of weed cutting methods. These results were further supported in the PCA analysis as sites subjected to weed cutting with boat (deep) were strongly separated from uncut controls, although uncut controls were only slightly 
separated from stream sites subjected to weed cutting with scythe. Importantly, the strongest separation occurred along the PC1-axis, mainly reflecting physical/hydromorphological parameters exerting strong influence on DHI scores. This may indicate that the overall habitat quality can be impaired by intense weed cutting using the boat (deep) method. Conversely, this could indicate a historically stronger need for flood protection in stream catchments subjected to the boat (deep) method and that previous dredging and channelization had severely reduced the habitat quality before the boat (deep) method was implemented. These potential explanations cannot be separated or validated with our data. However, the destructive potential of the boat (deep) method cannot be ruled out, and we emphasize that environmental impacts of the boat (deep) method should be further scrutinized before it is further implemented in stream systems as standard weed cutting practice.

Some individual parameters in DHI, for example, submerged roots, width of undisturbed riparian buffer, and ochre pollution, are unlikely to be directly influenced by weed cutting, while other parameters such as high-energy flow types, pool-riffle sequences, and width variation, can be directly or indirectly influenced by weed cutting (Pedersen et al., 2004). Since weed cutting influences current velocities, parameters that are affected by velocity (e.g. substrate composition (Pedersen et al., 2004)) can also be affected by weed cutting. Interestingly, several individual parameters, which were strongly correlated with DHI index scores, can be directly or indirectly influenced by weed cutting (pool-riffle sequences, high energy flow types, and substrate composition). In contrast, cross sectional profile and sinuosity also exerted strong influence along the PC1 axis indicating that streams subjected to more intensive weed cutting practice (especially the boat (deep) method) were more intensively channelized and dredged or that continuous weed cutting maintained the profiles of previous channelization. This further indicates that the intense weed cutting practices may have negatively influenced the general physical habitat quality of the streams. Although we cannot disentangle potential effects of past maintenance practice from the present weed cutting practice, our results should be used to conservatively protect the aquatic environment, and we suggest to halt the boat (deep) method until the potential strong negative effects on habitat quality compared to other weed cutting methods can be scientifically disproven in future studies.

Our results receive support from the scarce amount of studies published in international peer-reviewed journals. A study conducted in 68 small to medium-sized Danish streams showed that width variation and proportional coverage of silt was significantly lower and higher, respectively, in disturbed stream reaches (channelization and weed cutting) compared to less disturbed reaches (Pedersen and Friberg, 2009). Pedersen (2009) found a significantly higher variation in depth and width and higher substrate heterogeneity in reference streams compared to channelized streams subjected to weed cutting. Disentangling effects of dredging/channelization and weed cutting is likely confounded by a strong overlap in physical and ecological responses. A study conducted in small streams in Switzerland showed that both weed cutting and dredging increased mean depth and current velocity at the reach scale, and that the reduction in total plant biomass following stream interventions was highly comparable between the two methods (84\% and 94\%, respectively) (Kaenel and Uehlinger, 1999). Hence, co-occurrence of these management strategies probably additively magnifies the total impact on habitat quality in streams. Similar comparative studies need to be conducted to quantify physical effects of the boat (deep) method.

\subsection{Short-term effects of weed cutting methods on sediment transport and deposition}

Suspended sediment concentrations responded strongly to weed cutting with boat (deep) increasing from approximately 10 to $150300 \mathrm{mg} \mathrm{L}^{-1}$ for more than $2 \mathrm{~h}$ during and after weed cutting. In contrast, only vague increases in suspended sediment concentrations occurred during and after weed cutting with scythe with highest concentrations in the range of 20-25 $\mathrm{mg} \mathrm{L}^{-1}$. These differences may be explained by the boat (deep) method being substantially more pervasive with heavy machinery ploughing through the stream bed, hereby mobilizing the upper layers of fine sediments. Elevated levels of suspended sediment concentrations following weed cutting have been reported in New Zealand lowland streams (Greer et al., 2017), where suspended sediment increased up to 15 $687 \mathrm{mg} \mathrm{L}^{-1}$. Stream bed disturbance during mechanical excavation of macrophytes increased suspended sediment concentrations in both short-term (h) and long-term (77 days), indicating that without macrophytes higher amounts of fine sediments are continually eroded and resuspended. In this context, sediment erosion during peak flow episodes can be expected to increase following boat (deep) cutting compared to cutting with scythe, since cutting with scythe leaves the majority of standing macrophyte beds untouched.

Importantly, the levels of suspended sediments following cutting with boat (deep) may be harmful to fish, in particular salmonid spawning grounds (Greer et al., 2015) and may have strong impacts on macroinvertebrate communities through mass drift initiation (Doeg and Milledge, 1991), reduced abundance of especially mayflies (Ephemeroptera), stoneflies (Plecoptera), and caddisflies (Trichoptera), and increased mortality of deposited insect eggs (Everall et al., 2018). However, Jones et al. (2012) underlined that many of the observed impacts of suspended sediment transport on macroinvertebrate communities occur as a consequence of sediment deposition, although disentangling effects of suspended sediments and sediment deposition was confounded by overlapping effects as well as overlapping co-occurrence. Hence, Jones et al. (2012) argued that quantification of sediment deposition needs to be quantified for a sufficiently robust interpretation of potential ecological effects of suspended sediment.

Downstream sediment deposition during weed cutting with

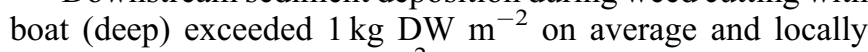

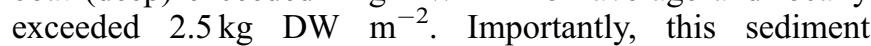
deposition was completed within $1 \mathrm{~h}$ being substantially faster compared to sedimentation processes in natural stream systems or in stream systems affected by anthropogenically driven landscape erosion (Wood and Armitage, 1997). The observed intensity of sediment deposition can efficiently clog interstitial spaces in coarser substrate types disabling or impeding hyporheic flow and nutrient exchange as well as 
impairing hyporheic habitats. As such, the observed levels of sediment deposition would likely impair existing salmonid spawning grounds and egg survival and potentially add to an overall change in macroinvertebrate communities towards higher abundance of polyvoltine generalists and lower abundance of species with more specific habitat requirements and longer life cycles such as most Ephemeroptera, Plecoptera, and Trichoptera taxa (Wood and Armitage, 1997; Larsen and Ormerod, 2010; Larsen et al., 2011).

This comparative before-after part of our study was not replicated and cover a short temporal scale, hence the results should be interpreted as indicative for potential environmental effects of the boat (deep) method. Validation of the results requires further research initiatives covering multiple streams and ecological endpoints through a substantially extended study period. However, the results showing that weed cutting with the boat (deep) method may cause mass sediment transport comparable to natural storm flow events (Kronvang et al., 1997). In contrast to storm driven sediment transport, sediment transport events mediated by mechanical weed cutting most likely occur during normal or low flow scenarios in summer or early autumn months normally affiliated with less precipitation. Hence, transport distance of eroded sediment will most likely be shorter and sediment deposition faster following mechanical weed cutting compared to storm flow events, and the accelerated sediment deposition rates may therefore cause significantly higher ecological impacts compared to storm driven sediment transport. Based on our preliminary results indicating that the boat (deep) method may be affiliated with new types of environmental effects that can have serious consequences for fish and macroinvertebrates, we emphasize that further studies, addressing these potential environmental effects, should be conducted before the boat (deep) method is accepted and implemented as an alternative management practice on a national scale.

\subsection{Short-term effects of weed cutting methods on oxygen conditions}

Dissolved oxygen concentrations decreased from $\sim 6$ to $5.3 \mathrm{mg} \mathrm{L}^{-1}$, and BOD increased from $\sim 2$ to $4 \mathrm{mg} \mathrm{L}^{-1}$ during and up to $1 \mathrm{~h}$ after weed cutting with boat (deep) whereas no visible changes were observed during and after weed cutting with scythe. These changes in oxygen conditions following cutting with boat (deep) were likely caused by increased microbial activity, reflected by the increased BOD. The observed decrease in oxygen concentration may be harmful for salmonid fish, but the duration of reduced oxygen concentrations was probably not sufficient to cause temporary changes in existing fish communities (Crabtree et al., 2012). Moreover, general diel and seasonal fluctuations in oxygen concentrations most likely exceed the observed fluctuations during the $24 \mathrm{~h}$ observation period emphasizing that the observed drop in oxygen concentrations during weed cutting with the boat (deep) method probably is less relevant in a broader context (e.g. Mulholland et al., 2005). Nevertheless, we recommend that the boat (deep) method should be performed during mid-day where oxygen concentrations in general are highest in order to minimize the risk of exceeding crucial ecological thresholds for minimum oxygen concentrations.

\section{Perspectives}

Climate change has altered weather conditions in the Northern European countries towards more frequent extreme precipitation events, and extreme precipitation has increased faster than total wet-day precipitation (Sillmann et al., 2013). These alterations in weather conditions are expected to further intensify in coming decades, and the extreme precipitation events are expected to increasingly occur during autumn and winter (IPCC, 2020). Consequently, prevention of flooding risk in agricultural and urban areas put tremendous pressures on managing authorities by public discussions requesting the need to find solutions. One suggested solution is increasing frequency of aquatic plant removal and changing removal methods towards more intense managing that simultaneously maintains or even increases stream depth - such as the boat (deep) method - to maximize stream discharge capacity. Our study shows that high intensity weed cutting may decrease physical habitat quality as well as initiate mass sediment resuspension and sedimentation events potentially hampering ecological quality. Although requiring further experiments and scientific evidence, our results indicate that fulfilling the legal requirements of the EU WFD may be impaired by such changes in management practice, and we strongly recommend that more research is conducted addressing hydromorphological and ecological effects of the boat (deep) method before implementing this at the national scale in Denmark and in other countries.

We additionally emphasize that climate change induced weather changes on the Northern hemisphere, additionally, are proposed to increasingly intensify summer droughts which may be highly critical for stream dwelling organisms. During such drought periods, macrophyte beds would increase the stream retention capacity of water, consequently fulfilling important roles targeting the avoidance of drought conditions in stream systems. Hence, macrophyte removal, especially during summer, should also be seen and evaluated in context of drought avoidance.

\section{Declarations}

The authors declare no conflict of interest.

\section{Supplementary Material}

Table S1. Overview of the physical parameters quantified in the Danish Habitat Index.

Table S2. Sedimentation of suspended sediment during weed cutting with boat (deep) in Dybvad stream.

Figure S1. Mean value and standard error of pool-riffle sequences, sinuosity, and cross-sectional profile for the stream groups boat (deep), boat (shallow), scythe, and uncut.

The Supplementary Material is available at https://www.kmaejournal.org/10.1051/kmae/2021009/olm.

Acknowledgements. We thank Jytte Erfurt and Jianlian Wienke for help with data management and Tinna Christensen for graphical improvements. Benoît Demars gave constructive comments to the article. Moreover, we are thankful to Peter Munk Andersen (Aalborg municipality) who helped organize 
and synchronize field activities and Sloths Naturpleje who executed weed cutting with boat (deep) and was helpful and collaborative during our field activities. This study was funded by Aalborg Municipality. Finally, we wish to thank two anonymous reviewers for constructive comments that helped to significantly improve the article.

\section{References}

Baattrup-Pedersen A, Riis T. 1999. Macrophyte diversity and composition in relation to substratum characteristics in regulated and unregulated Danish streams. Freshwat Biol 42: 375-385.

Baattrup-Pedersen A, Riis T. 2004. Impacts of different weed cutting practices on macrophyte species diversity and composition in a Danish stream. River Res Appl 20: 103-114.

Baattrup-Pedersen A, Larsen SE, Riis T. 2002. Long-term effects of stream management on plant communities in two Danish lowland streams. Hydrobiologia 481: 33-45.

Baattrup-Pedersen A, Larsen SE, Riis T. 2003. Composition and richness of macrophyte communities in small Danish streams influence of environmental factors and weed cutting. Hydrobiologia 495: 171-179.

Baattrup-Pedersen A, Ovesen NB, Larsen SE, Andersen DK, Riis T, Kronvang B, Rasmussen JJ. 2018. Evaluating effects of weed cutting on water level and ecological status in Danish lowland streams. Freshw Biol 63: 652-661.

Bal KD, Meire P. 2009. The influence of macrophyte cutting on the hydraulic resistance of lowland rivers. J Aquat Plant Manag 47: 65-68.

Bal KD, Struyf E, Vereecken H, Viaene P, De Doncker L, de Deckere E, Mostaert F, Meire P. 2011. How do macrophyte distribution patterns affect hydraulic resistances? Ecol Eng 37: 529-533.

Bal KD, Verschoren V, Sara JR, Meire P, Schoelynck J. 2017. Consequences of different cutting regimes on regrowth and nutrient stoichiometry of Sparganium erectum L. and Potamogeton natans L. Riv Res Appl 33: 1420-1427.

Caffrey JM. 1993. Plant management as an integrated part of Ireland's aquatic resources. Hydroécol Appl 5: 77-96.

Crabtree B, Horn J, Johnson I. 2012. Review of urban pollution management standards against WFD requirements. Environment Agency, Horizon House, Bristol. Document code: LI 7373, 78pp.

Curran JC, Hession WC. 2013. Vegetative impacts on hydraulics and sediment processes across the fluvial system. J Hydrol 505: 364376.

Dawson F. 1978. Aquatic plant management in semi-natural streams. J Environ Manage 6: 213-221.

Doeg TJ, Milledge GA. 1991. Effect of experimentally increasing concentrations of suspended sediment on macroinvertebrate drift. Aust J Mar Freshw Res 42: 519-526.

Eekhout JPC, Hoitink AJF, de Brouwer JHF, Verdonschot PFM. 2015. Morphological assessment of reconstructed lowland streams in the Netherlands. Adv Wat Resour 81: 161-171.

Everall NC, Johnson MF, Wood P, Mattingley L. 2018. Sensitivity of the early life stages of a mayfly to fine sediment and orthophosphate levels. Environ Pollut 237: 792-802.

Fox AM, Murphy KJ. 1990. The efficacy and ecological impacts of herbicide and cutting regimes on the submerged plant communities of four British rivers. I. A comparison of management efficacies. J Appl Ecol 27: 520-540.
Frasson RPDM, Pavelsky TM, Fonstad MA, Durand MT, Allen GH, Schuman G, Lion C, Beighley RE, Yang X. 2019. Global relationships between river width, slope, catchment area, meander wavelength, sinuosity, and discharge. Geophys Res Lett 46: 3252-3262.

Greer MJC, Crow SK, Hicks AS, Closs GP. 2015. The effects of suspended sediment on brown trout (Salmo trutta) feeding and respiration after macrophyte control. $N Z$ J Mar Freshw Res 49: 278-285.

Greer MJC, Hicks AS, Crow SK, Closs GP. 2017. Effects of mechanical macrophyte control on suspended sediment concentrations in streams. N Z J Mar Freshw Res 51: 254-278.

Greig SM, Sear DA, Carling PA. 2007. A review of factors influencing the availability of dissolved oxygen to incubating alsmonid embryos. Hydrol Proc 21: 323-334.

Hothorn T, Bretz F, Westfall P. 2008. Simultaneous inference in general parametric models. Biom J 50: 346-363.

IPCC. 2020. Summary for policymakers. In Masson-Delmotte V, P. Zhai H-O, Pörtner D, et al., eds. Global Warming of $1.5^{\circ} \mathrm{C}$. An IPCC Special Report on the impacts of global warming of $1.5^{\circ} \mathrm{C}$ above pre-industrial levels and related global greenhouse gas emission pathways, in the context of strengthening the global response to the threat of climate change. World Meteorological Organization, Geneva, Switzerland, 32 pp.

Jones JI, Murphy JF, Collins AL, Sear DA, Naden PS, Armitage PD. 2012. The impact of fine sediment on macroinvertebrates. River Res Appl 28: 1055-1071.

Kaenel BR, Uehlinger U. 1999. Aquatic plant management: ecological effects in two streams of the Swiss Plateau. Hydrobiologia 415: 257-263.

Kronvang B, Laubel A, Grant R. 1997. Suspended sediment and particulate phosphorus transport and delivery pathways in an arable catchment, Gelbæk stream, Denmark. Hydrol Process 11: 627-642.

Lamba J, Thompson AM, Karthikeyan KG, Fitzpatrick FA. 2015. Sources of fine sediment stored in agricultural lowland streams, Midwest, USA. Geomorphology 236: 44-53.

Larsen S, Ormerod SJ. 2010. Combined effects of habitat modification on trait composition and species nestedness in river invertebrates. Biol Conserv 143: 2638-2646.

Larsen S, Pace G, Ormerod SJ. 2011. Experimental effects of sediment deposition on the structure and function of macroinvertebrate assemblages in temperate streams. River Res Appl 27: 257-267.

Leggieri L, Feijoo C, Giorgi A, Ferreiro N, Acuna V. 2013. Seasonal weather effects on hydrology drive the metabolism of non-forest lowland streams. Hydrobiologia 716: 47-58.

Mulholland, PJ, Houser JN, Maloney KO. 2005. Stream diurnal dissolved oxygen profiles as indicators of in-stream metabolism and disturbance effects: Fort Benning as a case study. Ecol Indic 5: $243-252$.

Oksanen J, Guillaume, Blanchet F, Friendly M, Roland K, Legendre P, McGlinn D, Minchin PR, O'Hara RB, Simpson GL, Solymos P, Stevens HH, Szoecs E, Wagner H. 2018. Community ecology package "vegan", version 2.3-1.

Old GH, Naden PS, Rameshwaran P, Acreman MC, Baker S, Edwards FK, Sorensen JPR, Mountford O, Gooddy DC. 2014. Instream and riparian implications of weed cutting in a chalk river. Ecol Eng 71: 290-300.

Österling EM. 2018. Sedimentation affects emergence rate of host fish fry in unionoid mussel streams. Anim Conserv 22: 444-451. 
Pardo I, García L. 2016. Water abstraction in small lowland streams: unforeseen hypoxia and anoxia effects. Sci Total Environ 568: 226-235.

Pedersen ML. 2009. Effects of channelisation, riparian structure and catchment area on physical habitats in small lowland streams. Fundam Appl Limnol 174: 89-99.

Pedersen ML, Friberg N. 2009. Influence of disturbance on habitats and biological communities in lowland streams. Fundam Appl Limnol 174: 27-41.

Pedersen ML, Friberg N, Larsen SE. 2004. Physical habitat structure in Danish lowland streams. River Res Appl 20: 653-669.

Pedersen ML, Baattrup-Pedersen A, Rorth FR, Madsen TV, Larsen SE. 2011. Short-term impacts of weed cutting on physical habitats in lowland rivers - The importance of initial environmental conditions. Polish J Environ Stud 20: 1271-1280.

Pinheiro J, Bates D, DebRoy S, Sarkar D, R Core Team. 2020. nlme: Linear and Nonlinear Mixed Effects Models. R package version 3.1-150, https://CRAN.R-project.org/package=nlme.

R Core Team. 2020. R: A language and environment for statistical computing. R Foundation for Statistical Computing, Vienna, Austria. URL https://www.R-project.org/.
Rovira A, Alcaraz C, Trobajo R. 2016. Effects of plant architecture and water velocity on sediment retention by submerged macrophytes. Freshw Biol 61: 758-768.

Rubin JF. 1995. Estimating the success of natural spawning salmonids in streams. J Fish Biol 46: 603-622.

Sillmann J, Kharin VV, Zwiers FW, Zhang X, Bronaugh D. 2013. Climate extremes indices in the CMIP5 multimodel ensemble: part 2. Future climate projections. J Geophys Res 118: 2473-2493.

Verdonschot PFM, Nijboer RC. 2002. Towards a decision support system for stream restoration in the Netherlands: an overview of restoration projects and future needs. Hydrobiologia 478: 131-148.

Verschoren V, Shchoelynck J, Cox T, Schoutens K, Temmerman S, Meire P. 2017. Opposing effects of aquatic vegetation on hydraulic functioning and transport of dissolved and organic particulate matter in a lowland river: a field experiment. Ecol Eng 105: 221-230.

Wildhaber YS, Michel C, Epting J, Wildhaber RA, Huber E, Huggenberger P, Burkardt-Holm P, Alewell C. 2014. Effects of river morphology, hydraulic gradients, and sediment deposition on water exchange and oxygen dynamics in salmonid redds. Sci Total Environ 470: 488-500.

Wood PJ, Armitage PD. 1997. Biological effects of fine sediment in the lotic environment. Environ Manage 21: 203-217.

Cite this article as: Rasmussen JJ, Kallestrup H, Thiemer K, Alnøe AB, Dalsgaard Henriksen L, Larsen SE, Baattrup-Pedersen A. 2021. Effects of different weed cutting methods on physical and hydromorphological conditions in lowland streams. Knowl. Manag. Aquat. Ecosyst., 422, 10. 